\title{
Coverage-dependent adsorption geometry of octithiophene on Au(111)
}

\author{
Erwan Varene, ${ }^{a}$ Lea Bogner, ${ }^{a}$ Stephan Meyer, ${ }^{a}$ Yan Pennec ${ }^{b}$ and Petra Tegeder ${ }^{a, *}$ \\ Received Xth XXXXXXXXXX 20XX, Accepted Xth XXXXXXXXX 20XX \\ First published on the web Xth $X X X X X X X X X X 200 X$ \\ DOI: 10.1039/b000000x
}

The adsorption behavior of $\alpha$-octithiophene (8T) on the $\mathrm{Au}(111)$ surface as function of 8T coverage has been studied with lowtemperature scanning tunneling microscopy, high resolution electron energy loss spectroscopy as well as with angle-resolved twophoton photoemission and ultraviolet photoemission spectroscopy. In the sub-monolayer regime 8T adopts a flat-lying adsorption geometry. Reaching the monolayer coverage the orientation of $8 \mathrm{~T}$ molecules changes towards a tilted configuration, with the long molecular axis parallel to the surface plane, facilitating attractive intermolecular $\pi$ - $\pi$-interactions. The photoemission intensity from the highest occupied molecular orbitals (HOMO and HOMO-1) possesses a strong dependence on the adsorption geometry due to the direction of the involved transition dipole moment for the respective photoemission process. The change in molecular orientation as a function of coverage in the first molecular layer mirrors the delicate balance between intermolecular and molecule/substrate interactions. Fine tuning of these interactions opens up the possibility to control the molecular structure and accordingly the desirable functionality.

\section{Introduction}

Organic molecules are promising candidates for applications in optoelectronic devices, for example in organic photovoltaic cells (OPVC) $)^{1,2}$, organic light-emitting diodes (OLEDs) $)^{1,3}$ or organic field effect transistors (OFETs) ${ }^{3-5}$. Due to their semiconducting properties, oligothiophenes show a high potential for the above mentioned applications. The variation of the chain length of these $\pi$-conjugated compounds allows to tune their optical and electronic properties ${ }^{6-10}$. For instance, it has been shown by high resolution electron energy loss spectroscopy (HREELS) that the size of the gap between the highest occupied molecular orbital (HOMO) and the lowest unoccupied molecular orbital (LUMO) can be tuned by the number of thiophene rings ${ }^{11}$. So far, the longest unsubstituted $\alpha$-oligothiophene which has been synthesized is the $\alpha$-octithiophene (8T). It possesses the highest carrier mobility in the class of unsubstituted oligothiophenes ${ }^{12,13}$.

It is well-known that the properties of interfaces between active layers are crucial for the performance of optoelectronic devices. For oligothiophenes it has been shown that the orientation of the molecules is of particular importance ${ }^{14}$ especially for the light emission/absorption and charge transport properties. Intermolecular interaction competes with molecule/substrate interaction both defining the adsorption geometry and the arrangement of the molecular film and ac-

${ }^{a}$ Freie Universität Berlin, Fachbereich Physik, Arnimallee 14, 14195 Berlin, Germany.

Email: petra.tegeder@physik.fu-berlin.de

${ }^{b}$ Department of Chemistry and Physics and Astronomy, University of British Columbia, Vancouver, B.C. V6T 1Z4, Canada. cordingly the electronic structure of the system. For instance, $\alpha$-sexithiophene (6T) has been found to form well-ordered films with molecules flat-lying on $\mathrm{Au}$ films while tilted by about $70^{\circ}$ with respect to the surface plane on $\mathrm{Ag}$ and $\mathrm{Cu}$ films, respectively ${ }^{15}$. Since the quality and the properties of these interfaces are substantially dominated by the adsorption of the first molecular layer, it is important to gain detailed information on its geometry. Although the adsorption behavior of 6T on different metal surfaces has been intensively studied ${ }^{16-25}$, so far only two recent scanning tunneling microscopy (STM) studies investigated the adsorption of $8 \mathrm{~T}$ on $\mathrm{Cu}(111)^{26}$ and $\mathrm{Au}(111)^{27}$. In the latter we analyzed the adsorption behavior ranging from single molecules to the first two layers of $8 \mathrm{~T}$ on $\mathrm{Au}(111)$. Thereby, we proposed that the molecular adsorption geometry is changing from flat-lying $8 \mathrm{~T}$ in the sub-monolayer regime to a tilted geometry in the first monolayer. However, no conclusive prove on the adsorption geometry of $8 \mathrm{~T} / \mathrm{Au}(111)$ on the basis of the STM results could be given.

In the present contribution we utilized complementary experimental techniques, namely STM, HREELS, as well as two-photon photoemission (2PPE) and ultraviolet photoemission spectroscopy (UPS) in order to obtain a comprehensive picture on the adsorption behavior of $8 \mathrm{~T}$ on $\mathrm{Au}(111)$ as a function of 8T-coverage. We found that $8 \mathrm{~T}$ adopts a planar (flat-lying) adsorption geometry in the low-coverage regime ( $\ll 1$ monolayer, ML), whereas for higher coverage $(\approx 1 \mathrm{ML})$ the molecules realign to a tilted configuration, with the long molecular axis parallel to the surface. This variation in geometry is accompanied by a change in the photoemission intensity from the HOMO and HOMO-1 due to the modification in the 
direction of the transition dipole moment for photoionization.

\section{Experimental Section}

All experiments were performed under ultrahigh vacuum (UHV) conditions (base pressure $10^{-10}$ mbar) using three different setups, each holding one of the complementary experimental techniques used in this experiment: scanning tunneling microscopy (STM), high resolution electron energy loss spectroscopy (HREELS), and two-photon photoemission (2PPE) spectroscopy.

The Au(111) surface was prepared by repeated cycles of $\mathrm{Ar}^{+}$sputtering $\left(1.5 \mathrm{keV}, 5 \mu \mathrm{A} / \mathrm{cm}^{2}\right)$ followed by annealing at $800 \mathrm{~K} .8 \mathrm{~T}$ molecules (Advanced Technology and Industrial Co., Ltd.) were first out-gassed in vacuum for several hours and then evaporated from an organic molecular beam effusion cell held at $510 \mathrm{~K}$ at a substrate temperature of $300 \mathrm{~K}$.

The STM (Createc based design) was operated typically at $15 \mathrm{~K}$ to obtain high-resolution topographic data. Topographic data were acquired in the constant current mode, with typical tunneling resistances in the range of 10-104 $\mathrm{M} \Omega$.

The HREEL spectra were recorded at a sample temperatures of $100 \mathrm{~K}$, in both specular $\left(\theta_{i}=\theta_{r}=60^{\circ}\right)$ and offspecular $\left(\theta_{i}=53^{\circ} ; \theta_{r}=60^{\circ}\right)$ scattering geometries. The energy of the primary electrons was set to $3.5 \mathrm{eV}$, with an overall resolution around $3.1 \mathrm{meV}$ measured as the full-width at halfmaximum of the elastic peak. In specular scattering geometry, the spectral signal contains both dipole- and impact-scattering components. The selection rule for dipole-scattering at metal surfaces is the same as that for infrared reflection absorption spectroscopy. This means that only vibrations with a nonvanishing component of the dipole moment change normal to the metal surface are observable. Thus making HREELS ideal for characterizing the geometrical structure and predominant orientation of adsorbates. To distinguish between dipoleand impact-scattering components, off-specular spectra arising only from impact-scattering were obtained at an incident angle of $53^{\circ}$ (corresponding to $7^{\circ}$ off-specular), keeping the angle of the reflected beam unchanged.

For the 2PPE measurements a tunable femtosecond (fs) laser system, consisting of a Ti/sapphire oscillator in combination with a $300 \mathrm{kHz}$ regenerative amplifier, was used. It supplies pulses with a central wavelength of $830 \mathrm{~nm}$. Twice performed frequency doubling of the fundamental beam in $\beta$ barium borate (BBO) crystals yields pulses with a photon energy of $6 \mathrm{eV}$. Furthermore is the output used to pump an optical parametrical amplifier (OPA), which yields photons with a tunable energy in the range from 1.7 to $2.7 \mathrm{eV}$. Through frequency doubling in a BBO crystal, the photon energy range from 3.4 to $5.4 \mathrm{eV}$ is achieved. After thorough temporal compression, pulses with a duration around $60 \mathrm{fs}$ are obtained. These are focused onto the sample under an angle of $45^{\circ}$ with respect to the surface normal. Photoelectrons are detected in a custom-built time-of-flight (TOF) spectrometer and are analyzed with respect to their kinetic energy $\left(\mathrm{E}_{\mathrm{kin}}\right)$. The energy resolution of the TOF spectrometer depends on the kinetic energy of the electrons, it is $20 \mathrm{meV}$ at $\mathrm{E}_{\mathrm{kin}}=1 \mathrm{eV}$ (for details see Ref. ${ }^{28,29}$ ).

\section{Results and discussion}

We first studied the adsorption behavior of $8 \mathrm{~T}$ in the sub- and monolayer regime with STM. It has been shown that in the sub-monolayer regime $8 \mathrm{~T}$ molecules adsorb preferentially at the step edges and the fcc packing regions of the reconstructed $\mathrm{Au}(111)$ surface without forming ordered islands or exhibiting any other indication of self-assembly. The sub-molecular resolution STM image of a single molecule, as shown in Fig. 1(a), exhibits 8 regular maxima which are related to the 8 thiophene rings within the molecule ${ }^{27}$. In the monolayer regime
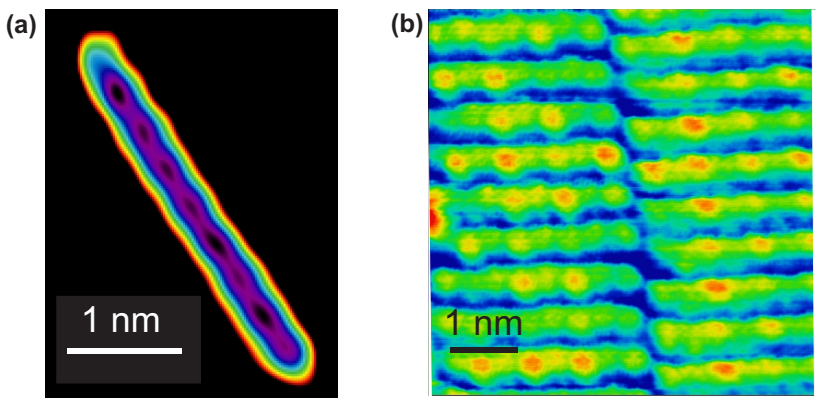

Fig. 1 (a) Sub-molecular resolution STM image of a single molecule exhibiting 8 features corresponding to the 8 thiophene rings within the molecule. (b) High resolution STM image of a monolayer $8 \mathrm{~T} / \mathrm{Au}(111)\left(V_{s}=2 \mathrm{~V}, I_{t}=200 \mathrm{pA}\right)$. Four bright features can be observed on the molecules, which are assigned to the sulfur (see text for details).

8T possesses a well-ordered and densely packed structure in which the molecules are aligned in rows parallel to each others backbone as shown in Fig.1(b). The formation of selfassembled layers with rising coverage implies the development of attractive intermolecular interactions in contrast to the sub-monolayer regime and may be related to a reorientation. The high resolution STM image of 1 ML 8T on Au(111) (Fig.1(b)) shows only 4 dark depressions per molecule instead of the 8 observed for the single molecules. This observation may be attributed to a change in adsorption geometry from planar, flat-lying molecules in the sub-monolayer regime to a tilted configuration in the monolayer. The latter would allow for attractive intermolecular $\pi-\pi$-interaction ( $\pi$-stacking). Note that the $8 \mathrm{~T}$ bilayer exhibits the same structure as the $\mathrm{ML}^{27}$.

To gain a deeper insight into the adsorption properties of 
8T on $\mathrm{Au}(111)$ as a function of coverage we performed angular dependent HREELS measurements (Fig. 2). The HREEL spectra shown in Fig. 2 (a) and (b) are recorded in specular and off-specular geometry. For a sub-monolayer coverage

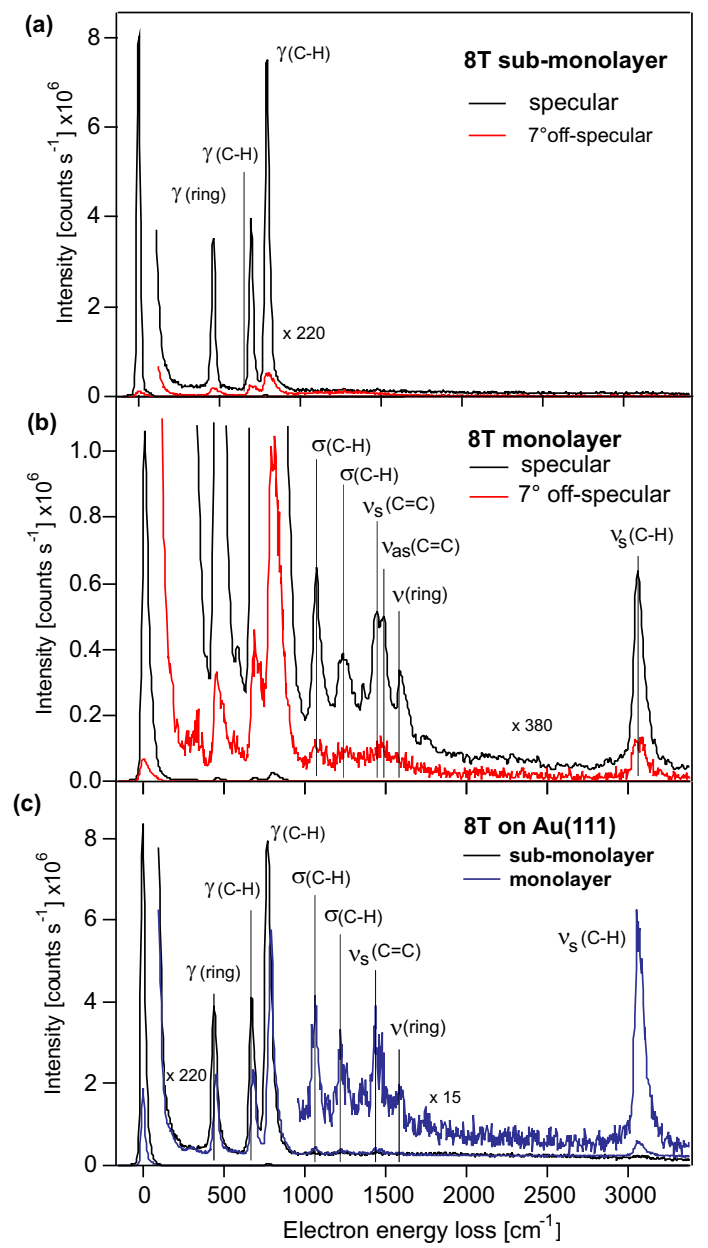

Fig. 2 HREEL spectra recorded with a primary electron energy of $3.5 \mathrm{eV}$ of $8 \mathrm{~T} / \mathrm{Au}(111)$ as a function of coverage: (a) sub-monolayer and (b) monolayer $8 \mathrm{~T}$ measured in specular and $7^{\circ}$ off-specular scattering geometry. (c) Comparison between HREEL spectra for a sub-ML and $1 \mathrm{ML} 8 \mathrm{~T}$ recorded in specular scattering geometry.

(Fig. 2 (a)), the specular spectrum is dominated by three very intense features, which can be assigned to out-of-plane vibrations, namely the ring deformation $\left(\gamma\left(\right.\right.$ ring): $\left.441 \mathrm{~cm}^{-1}\right)$ and to $\mathrm{C}-\mathrm{H}$ deformation modes $\left(\gamma(\mathrm{C}-\mathrm{H}): 674 \mathrm{~cm}^{-1}, 774 \mathrm{~cm}^{-1}\right)$, respectively. The vibrational frequencies and the assignments are listed in Table 1 together with the literature values of vibrational modes of condensed $8 \mathrm{~T}^{30}$. In off-specular scattering geometry these features become very weak indicating that their intensities are predominantly originating from dipolescattering. In-plane modes of $8 \mathrm{~T}$ located in the energy range between $1000-1500 \mathrm{~cm}^{-1}$ in the infrared spectrum of con-
Table 1 Vibrational frequencies (in $\mathrm{cm}^{-1}$ ) and assignments for sub-ML and ML 8T adsorbed on Au (111), and for condensed 8T, respectively $[v$ : stretching ; $\sigma$ : in-plane bending; $\gamma$ : out-of-plane bending; da indicates a strong dipole activity.]

\begin{tabular}{llll}
\hline Assignment & Sub-ML & ML & Solid $^{30}$ \\
\hline$\gamma($ ring $)$ & $441(\mathrm{da})$ & 449 & 455 \\
$\gamma(\mathrm{C}-\mathrm{H})$ & $674(\mathrm{da})$ & 682 & 687 \\
$\gamma(\mathrm{C}-\mathrm{H})$ & $774(\mathrm{da})$ & 794 & 790 \\
$\sigma(\mathrm{C}-\mathrm{H})$ & - & $1065(\mathrm{da})$ & 1047 \\
$\sigma(\mathrm{C}-\mathrm{H})$ & - & $1229(\mathrm{da})$ & 1222 \\
$v_{\mathrm{S}}(\mathrm{C}=\mathrm{C})$ & - & $1441(\mathrm{da})$ & 1424 \\
$v_{\mathrm{as}}(\mathrm{C}=\mathrm{C})$ & - & $1482(\mathrm{da})$ & 1491 \\
$v($ ring $)$ & - & $1582(\mathrm{da})$ & 1510 \\
$v_{\mathrm{s}}(\mathrm{C}-\mathrm{H})$ & - & $3075(\mathrm{da})$ & 3050 \\
\hline
\end{tabular}

densed $8 \mathrm{~T}^{30}$ are not observed in HREELS, whereas the outof-plane modes are strong. This leads to the clear indication that $8 \mathrm{~T}$ adopts a planar geometry in the low-coverage regime.

When increasing the coverage towards one monolayer, the number of vibrational modes visible in the spectrum rises significantly, pointing towards a change in the molecular adsorption geometry (see Fig. 2(b)). In detail, the observation of dipole active in-plane modes in the energy region between $1000-1500 \mathrm{~cm}^{-1}$ such as the $\mathrm{C}=\mathrm{C}$ symmetric and asymmetric stretch modes $\left(v_{s}(\mathrm{C}=\mathrm{C}): 1441 \mathrm{~cm}^{-1} ; v_{a s}(\mathrm{C}=\mathrm{C}): 1482 \mathrm{~cm}^{-1}\right)$, the $\mathrm{C}-\mathrm{H}$ bending mode $\left(\sigma(\mathrm{C}-\mathrm{H}): 1065\right.$ and $\left.1229 \mathrm{~cm}^{-1}\right)$, and the symmetrical stretch vibration of the $\mathrm{C}-\mathrm{H}$ group $\left(v_{s}(\mathrm{C}-\mathrm{H})\right.$ : $\left.3057 \mathrm{~cm}^{-1}\right)$, demonstrates that the molecules are tilted with respect to the substrate. Fig. 2(c) represents a comparison between HREEL spectra recorded in specular scattering geometry for a sub-ML and a ML 8T. In addition to the presence of dipole active in-plane modes at a coverage of $1 \mathrm{ML}$, the out-of-plane modes at 441,674, and $774 \mathrm{~cm}^{-1}$ loose intensity compared to the sub-ML spectrum, which also underline the coverage dependent reorientation. Thus from the vibrational analysis we conclude that $8 \mathrm{~T}$ molecules change their adsorption geometry from flat-lying in the sub-ML regime to a tilted geometry when reaching a monolayer coverage.

Generally, the molecular adsorption structure is governed by the strength of adsorbate/substrate interaction, viz. the electronic coupling strength and adsorbate/adsorbate interaction. The formation of well-ordered, densely packed rows with increasing $8 \mathrm{~T}$ coverage indicates that at higher coverage attractive intermolecular interactions prevail in comparison to the sub-monolayer regime. The rise of attractive forces is associated with a molecular rearrangement from a flat to tilted adsorption geometry, allowing for intermolecular $\pi-\pi$ interaction ( $\pi$-stacking). By comparison, in the case of thiophene on $\mathrm{Au}(111)$ as well as on $\mathrm{Ag}(111)$ and $\mathrm{Cu}(111)$ it has been shown that the angle between the molecular plane and 
the surface increases with rising coverage, which has been attributed to intermolecular $\pi-\pi$-interaction ${ }^{31}$. Contrary, $\alpha$ sexithiophene (6T) on $\mathrm{Au}(111)$ adopts in both the sub-ML and monolayer regime a planar, flat-lying adsorption geometry ${ }^{18,19}$. The reason for the different adsorption behavior between 8T and 6T on $\mathrm{Au}(111)$ is not obvious since at least the electronic structure of both molecules on $\mathrm{Au}(111)$ is very similar $^{27,32}$. However, this demonstrates that with fine balance between intermolecular interactions and molecule/substrate interactions the molecular structure can be varied, resulting in desirable functionalities.

The change in adsorption geometry as a function of 8Tcoverage can also be observed by two-photon photoemission as will be shown in the following. Figure 3 (a) shows angulardependent two-color 2PPE measurements recorded with 2.18 $\mathrm{eV}$ and $4.36 \mathrm{eV}$ photons at 0.5 ML 8T/Au(111). At this coverage the molecules are still flat-lying. Two dominant features are observed and on the basis of photon energy dependent measurement (data not shown here), we can assign them to occupied or unoccupied electronic states. The broad feature around $E_{\text {Final }}-E_{F}=6.12 \mathrm{eV}$ contains contribution of the Shockley surface state (SS) located at $-0.42 \mathrm{eV}$ with respect to $E_{F}$ and the $n=1$ image potential state (IPS) at $0.6 \mathrm{eV}$ below the vacuum level (corresponding to $3.98 \mathrm{eV}$ above $E_{F}$ ) ${ }^{28}$. Note that both states show a dispersion. The peak at $E_{\text {Final }}-E_{F}$ $=5.78 \mathrm{eV}$ is an occupied state located at $-0.78 \mathrm{eV}$, which we attribute to photoemission from the HOMO of $8 \mathrm{~T}^{27}$. When turning the sample toward negative angles (see Fig. 4 (a)) the electric field of the incoming p-polarized light becomes more perpendicular to the molecular backbone of the flat-lying 8T, and obviously the photoemission intensity from the HOMO increases. It has been shown that the photoemission yield (I) from a respective state can depend on the angle of incidence of the laser pulses. Thus, $I$ should be proportional to the square of the projection of the electromagnetic field vector $\mathbf{E}_{\text {light }}$ onto the transition dipole moment for photoionization $\mu_{i o n}: I \propto\left|\mathbf{E}_{\text {light }} . \mu_{\text {ion }}\right|^{233}$. This reveals that the transition dipole moment for the photoemission from the HOMO is oriented nearly perpendicular to the molecular backbone.

Figure 4(b) displays a set of UPS spectra taken with $6 \mathrm{eV}$ photons at various $8 \mathrm{~T}$ coverages. The spectrum at $0.05 \mathrm{ML}$ shows a sharp feature labeled as SS at a binding energy of $-0.48 \mathrm{eV}$ with respect to $E_{F}$, which is associated with the Shockley surface state ${ }^{28}$. At higher coverages SS is quenched and new features appear. The peak labeled SS' at a binding energy of $-0.3 \mathrm{eV}$ is the surface state of the adsorbate-covered $\mathrm{Au}(111)$ surface. Its binding energy and dispersion (not shown here) is consistent with results obtained from other adsorbatecovered $\mathrm{Au}$ surfaces ${ }^{28}$. In addition two peaks are observed at binding energies of -0.8 and $-1.1 \mathrm{eV}$ which we attribute to photoemission from the HOMO and HOMO-1, respectively. Most striking is the opposed behavior of the photoemission inten- (a)

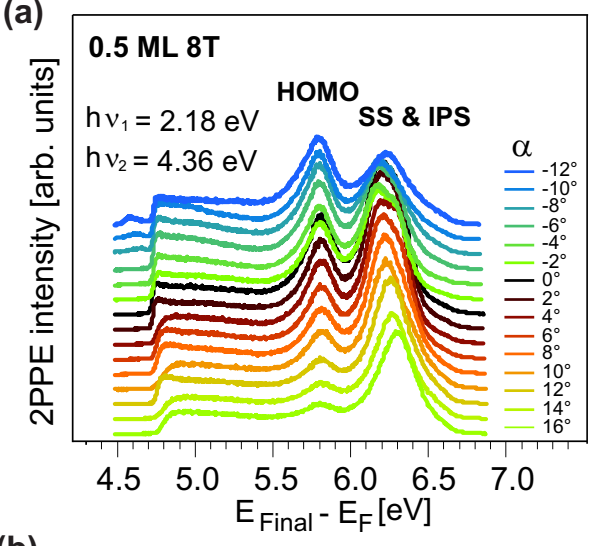

(b)

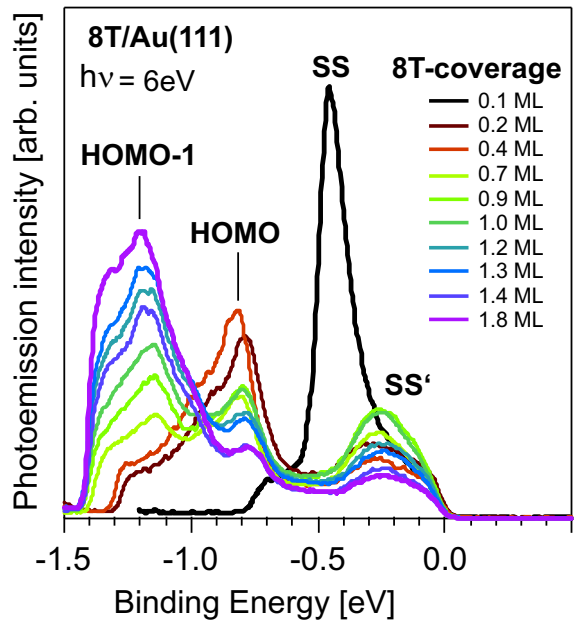

Fig. 3 (a) Angular-dependent two-color 2PPE measurements of 0.5 ML 8T/Au(111) measured with $2.18 \mathrm{eV}$ and $4.36 \mathrm{eV}$ photons. An increase of the the photoemission intensity from the HOMO is observed when turning the sample from positive to negative angles (see text). (b) Direct photoemission spectra recorded with a photon energy of $6 \mathrm{eV}$ at various $8 \mathrm{~T}$ coverages.

sity arising from the HOMO and HOMO-1 when increasing the amount of molecules. The photoemission intensity from the HOMO decreases while it increases for the HOMO-1 with rising coverage. As demonstrated above, when increasing the coverage toward the monolayer regime the absorption geometry of $8 \mathrm{~T}$ on $\mathrm{Au}(111)$ changes from flat-lying to a tilted configuration. Thus, the angle between the incoming p-polarized laser beam and the molecular plane increases and $I_{\text {HOMO }}$ decreases. Contrary, the increase of $I_{H O M O-1}$ shows that the photoionization transition dipole moment of the HOMO-1 lies parallel to the molecular backbone.

To corroborate our interpretation we applied symmetry selection rules (Laporte selection rule (i.e., a dipole transition is only allowed when the initial and final state have opposite parity) for planar all-trans conjugated $8 \mathrm{~T}$ with $C_{2 h}$ symmetry ${ }^{34}$ ). 
a)

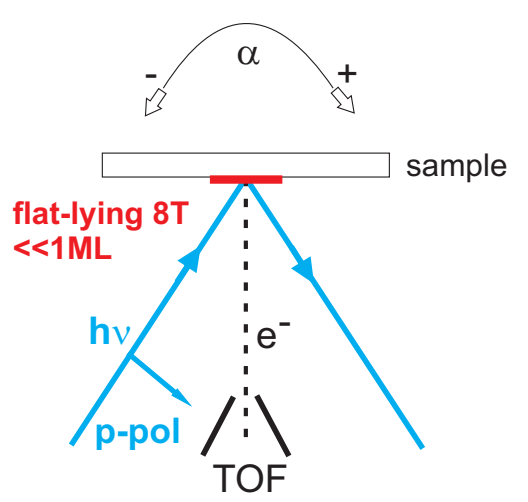

b)

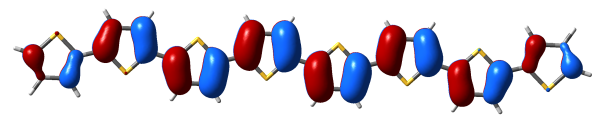

HOMO-1

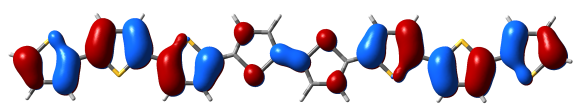

Fig. 4 (a) Scheme of the experimental setup for angle-resolved 2PPE measurements. For coverages below 1 ML 8T adopts a flat-lying adsorption geometry. (b) Calculated HOMO and HOMO-1 of a free standing 8T molecule using density functional theory (DFT). DFT calculations have been performed utilizing the hybrid functional $\mathrm{M} 6^{36}$ and the Dunning-Huzinaga basis set cc-pVDZ ${ }^{37}$ implemented in the Gaussian09 ${ }^{38}$ programm package. For visualization of the MOs GaussView $5^{39}$ has been employed.

The HOMO and HOMO-1 can be assigned to molecular orbitals with $B_{g}$ and $A_{u}$ symmetry, respectively (see Fig. 4 (b)). In the low coverage regime where the $8 \mathrm{~T}$ molecules lie flat on the surface, normal emission is allowed for the HOMO but forbidden for the HOMO-1, which does support our data. In the case of the higher coverage regime where the molecular plane is now tilted relative to the substrate plane, as well as to the detector, transition from the HOMO-1 is not forbidden anymore and emission from the HOMO can still occur, however with a lower probability (see figure 4 (a)). A further increase of the photoemission intensity from the HOMO-1 for coverages above 1 ML may be attributed to a higher number of molecules present on the surface. Note that also final state effects influence the photoemission intensities ${ }^{35}$.

Finally, it can be seen in figure 3 (b) that with increasing coverage the HOMO shifts by $40 \mathrm{meV}$ toward lower binding energies, while the HOMO-1 shifts by $70 \mathrm{meV}$ to a higher binding energy. To explain these effects we have to look at the Kohn-Sham orbitals shown in Fig. 4(b), which are calculated at the M06/cc-pVDZ level ${ }^{36,37}$ using Gaussian $09^{38}$. The HOMO appears to be located along the $\pi$-bonds in the plane of the molecule, thus the electronic coupling of this state is stronger in the sub-monolayer regime when the $8 \mathrm{~T}$ molecules lie flat on the surface and decreases with rising coverage since the $8 \mathrm{~T}$ molecules change their adsorption geometry. In contrast, the HOMO-1 is partially located at the sulfur atoms. This leads to a stronger electronic coupling in the tilted molecular configuration due to the thiophilicity of the Au surface.

\section{Conclusions}

In summary, the adsorption behavior of $\alpha$-octithiophene (8T) on $\mathrm{Au}(111)$ as a function of coverage, ranging from the submonolayer to monolayer regime has been analyzed with scanning tunneling microscopy (STM) and high resolution electron energy loss spectroscopy (HREELS). At a sub-monolayer coverage 8T molecules adsorb in a flat-lying adsorption geometry. Reaching the monolayer (ML) coverage the molecules realign forming a well-ordered film with the molecules are tilted with respect to the surface plane. This geometry permits attractive intermolecular $\pi-\pi$-interaction. The change in the adsorption geometry with increasing coverage has also been followed in photoemission experiments, namely ultraviolet photoemission spectroscopy (UPS) and angle-resolved two-photon photoemission (2PPE). The photoemission intensity from the HOMO and HOMO- 1 , which are located at -0.8 and $-1.1 \mathrm{eV}$ with respect the the Fermi level, exhibited a strong dependence on the adsorption geometry due to the direction of the involved transition dipole moment for the respective photoemission process. In addition the energetic position of both the HOMO and HOMO-1 shifted as the molecular orientation with respect to the surface changed. This effect has been explained by the different electronic coupling of the particular electronic state with the gold substrate.

Due to the change in the adsorption geometry as a function of $8 \mathrm{~T}$ coverage, it is very interesting to gain insights into charge carrier dynamics at the interface between $8 \mathrm{~T}$ and $\mathrm{Au}(111)$ as a function of the molecular orientation. The dynamics of charge carriers are of particular relevance for the performance of molecule-based optoelectronic devices.

\section{Acknowledgements}

Funding by the Deutsche Forschungsgemeinschaft (DFG) through the priority program SPP 1355 and the collaborative research center SFB 658 is gratefully acknowledged.

\section{References}

1 Y. Shirota, H. Kageyama, Chem. Rev., 2007, 107, 953. 
2 P. Peumans, A. Yakimov, S.R. Forrest, J. Appl. Phys., 2003, 93, 3693.

3 E. Menard, M.A. Meitl, Y. Sun, J.U. Park, D.J.L. Shir, Y.S. Nam, S. Jeon, J.A. Rogers, Chem. Rev., 2007, 107, 1117.

4 C.D. Dimitrakopoulos, P.R.L. Malefant, Adv. Mater., 2002, 14, 99.

5 C. Reese, Z. Bao, Mater. Today, 2007, 10, 20.

6 D. Fichou, J. Mater. Chem., 2000, 10, 571.

7 X. Yang, L. Wang, C. Wang, W. Long, Z. Shuai, Chem. Mater, 2008, 20 3205.

8 G. Horowitz, R. Hajlaoui, D. Fichou, A.E. Kassmi, J. Appl. Phys., 1999 85, 3202.

9 R. Yamada, H. Kumazawa, T. Noutoshi, S. Tanaka, H. Tada, Nano Lett. 2008, 8, 1237.

10 B.Q. Xu, X.L. Li, X.Y. Xiao, H. Sakaguchi, N.J. Tao, Nano Lett., 2005, $\mathbf{5}, 1491$.

11 H.J. Egelhaaf, D. Oelkrug, D. Oeter, Ch. Ziegler, W. Göpel, J. Mol. Struc., 1995, 348, 405; D. Oeter, H.J. Egelhaaf, Ch. Ziegler, D. Oelkrug, W. Göpel, J. Chem. Phys., 1994, 101, 6344.

12 S. Nagamatsu, K. Kaneto, R. Azumi, M. Matsumoto, Y. Yoshida, K. Yase, J. Phys. Chem. B, 2005, 109, 9374.

13 R. Bourguiga, M. Mahdouani, S. Mansouri, G. Horowitz, Eur. Phys. J. Appl. Phys., 2007, 39, 7.

14 G. Koller, S. Berkebile, J. Ivanco, F. Netzer, M. Ramsey, Surf. Sci., 2007, 601, 5683.

15 T. Okajima, S. Narioka, S. Tanimura, K. Hamano, T. Kurata, Y. Uehara T. Araki, H. Ishii, Y. Ouchi, K. Seki, T. Ogama, H. Koezuka, J Elect. Spectr. Rel. Phenom., 1996, 78, 379.

16 S. Prato, L. Floreano, D. Cvetko, V. De Renzi, A. Morgante, S. Modesti, F. Biscarini, R. Tamboni, C. Taliani, J. Chem. Phys. B, 1999, 103, 7788.

17 A.J. Mäkinen, J.P. Long, N.J. Watkins, Z.H. Kafafi, J. Phys. Chem. B, 2005, 109, 5790 .

18 M. Kiel, K. Duncker, C. Hagendorf, W. Widdra, Phys. Rev. B, 2007, 75, 195439.

19 H. Glowatzki, S. Duhm, K.-F. Braun, J.P. Rabe, N. Koch, Phys. Rev. B, 2007, 76, 125425.

20 K. Duncker, M. Kiel, A. Höfer, W. Widdra, Phys. Rev. B, 2008, 77, 155423.

21 G. Yoshikawa, M. Kigushi, S. Ikeda, K. Saiki, Surf. Sci., 2004, 559, 77.

22 H. Inoue, G. Yoshikawa, K. Saiki, Jpn. J. Appl. Phys., 2006, 3A, 1794.

23 M. Kiguchi, S. Entani, K. Saiki, G. Yoshikawa, Appl. Phys. Lett., 2004, 84, 3444; M. Kiguchi, G. Yoshikawa, S. Ikeda, K. Saiki, Surf. Sci., 2004, 566-568, 603.

24 A. Höfer, K. Duncker, M. Kiel, S. Wedekind, W. Widdra, Phys. Rev. B, 2011, 83, 075414

25 T. Wagner, D.R. Fritz, P. Zeppenfeld, Syn. Metals, 2011, 161, 2006

26 T. Kakudate, S. Tsukamoto, N. Nakaya, T. Nakayama, Surf. Sci., 2011, 605, 1021.

27 E. Varene, Y. Pennec, P. Tegeder, Chem. Phys. Lett., 2011, 515, 141.

28 S. Hagen, Y. Luo, R. Haag, M. Wolf, P. Tegeder, New. J. Phys., 2010, 12, 125022.

29 S. Hagen, P. Kate, M.V. Peters, S. Hecht, M. Wolf, P. Tegeder, Appl. Phys. A, 2008, 93, 253.

30 G. Louarn, J.P. Buisson, S. Lefrant, J. Phys. Chem., 1995, 99, 11399.

31 A Nambu, H Kondoh, I.Nakai, A Kmemiya, T. Ohta, Surf. Sci., 2003, 530, 101; P. K. Milligan, B. Murphy, D.Lennon, B. C. C Cowie, M Kadodwala, J. Phys. Chem. B, 2001, 105, 140; J. Nara, S. Higai, Y. Morikawa, T. Ohno, Appl. Surf. Sci., 2004, 237, 433; T. Matsuura, Y. Shimoyama, Eur. Phys., 2002, 7, 233; X. Chen, E.R. Frank, R. J. J. Hamers, Vac. Sci. Technol., B, 1996, 14, 1136; G. J. Su, H. M Zhang, L. J Wan, C. L. Bai, Surf. Sci., 2003, 531, L363.

32 E. Varene, I. Martin and P. Tegeder, J. Phys. Chem. Lett., 2011, 2, 252.

33 L. Gundlach, J. Szarko, L. D. Socaciu-Siebert, A. Neubauer, R. Ernstorfer and F. Willig, Phys. Rev. B, 2007, 75, 125320.
34 O. Laporte and W. F. Meggers, J. Opt. Soc. Am., 1925, 11, 459.

35 R.L. Kurtz, D. A. Browne, G.J. Mankey, J. Phys.: Condens. Matter, 2007, 19, 355001

36 Y. Zhao and D. G. Truhlar, Theor. Chem. Acc., 2008, 120, 215.

37 T. H. Dunning Jr., J. Chem. Phys., 1989, 90, 1007.

38 Frisch, M. J. Trucks, G. W. Schlegel, H. B. Scuseria, G. E. Robb, M. A. Cheeseman, J. R. Montgomery, J. A., Jr. ; Vreven, T. Kudin, K. N. Burant, J. C. Millam, J. M. Iyengar, S. S. Tomasi, J. Barone, V. Mennucci, B. Cossi, M. Scalmani, G. Rega, N. Petersson, G. A. Nakatsuji, H. Hada, M. Ehara, M. Toyota, K. Fukuda, R. Hasegawa, J. Ishida, M Nakajima, T. Honda, Y. Kitao, O. Nakai, H. Klene, M. Li, X. Knox, J. E. Hratchian, H. P. Cross, J. B. Adamo, C. Jaramillo, J. Gomperts, R. Stratmann, R. E. Yazyev, O. Austin, A. J. Cammi, R. Pomelli, C. Ochterski, J. W. Ayala, P. Y. Morokuma, K. Voth, G. A. Salvador, P. Dannenberg, J. J. Zakrzewski, V. G. Dapprich, S. Daniels, A. D. Strain, M. C. Farkas, O. Malick, D. K. Rabuck, A. D. Raghavachari, K. Foresman, J. B. Ortiz, J. V. Cui, Q. Baboul, A. G. Clifford, S. Cioslowski, J. Stefanov, B. B. Liu, G. Liashenko, A. Piskorz, P. Komaromi, I. Martin, R. L. Fox, D. J. Keith, T. Al-Laham, M. A. Peng, C. Y. Nanayakkara, A. Challacombe, M. Gill, P. M. W. Johnson, B. Chen, W. Wong, M. W. Gonzalez, C., Pople, J. A. Gaussian 03, revision C.02; Gaussian, Inc.: Wallingford CT, 2004

39 R. Dennington, T. K. J. Millam, GaussView Version 5”, Semichem Inc. Shawnee Mission KS 2009.

6 | Journal Name, 2010, [vol],1-6

This journal is @ The Royal Society of Chemistry [year] 